\title{
Correlation of Polymerization Conditions with Thermal and Mechanical Properties of Polyethylenes Made with Ziegler-Natta Catalysts
}

\author{
M. Anwar Parvez, ${ }^{1}$ Mostafizur Rahaman, ${ }^{1}$ M. A. Suleiman, ${ }^{1}$ \\ J. B. P. Soares, ${ }^{2}$ and I. A. Hussein ${ }^{1}$ \\ ${ }^{1}$ Department of Chemical Engineering, King Fahd University of Petroleum and Minerals, Dhahran 31261, Saudi Arabia \\ ${ }^{2}$ Department of Chemical Engineering, University of Waterloo, Waterloo, ON, Canada N2L 3G1
}

Correspondence should be addressed to I. A. Hussein; ihussein@kfupm.edu.sa

Received 14 October 2013; Revised 23 December 2013; Accepted 25 December 2013; Published 11 February 2014

Academic Editor: Giridhar Madras

Copyright ( 2014 M. Anwar Parvez et al. This is an open access article distributed under the Creative Commons Attribution License, which permits unrestricted use, distribution, and reproduction in any medium, provided the original work is properly cited.

\begin{abstract}
In this study, the synthesis of polyethylenes has been carried out with titanium-magnesium supported Ziegler-Natta catalysts in laboratory-scale reactors. A correlation of different polymerization conditions with thermal and mechanical properties of polyethylenes has been established. It is seen that there is lowering of molecular weight (Mw), polymer yield, and catalyst activity at high hydrogen pressure and high temperature. The Mw, polymer yield, and catalyst activity are improved with the increase in ethylene pressure. Dynamic mechanical analysis (DMA) results show that the increase in temperature and hydrogen pressure decreases storage modulus. The samples with higher Mw showed high activation energy. The melting point decreases with the increase in hydrogen pressure but increases slightly with the increase in ethylene pressure. It is seen that the increase in reaction temperature, ethylene pressure, and hydrogen pressure leads to an increase in crystallinity. The tensile modulus increases with the increase in hydrogen pressure and can be correlated with the crystallinity of polymer. The Mw has a major influence on the flow activation energy and tensile strength. But the other mechanical and thermal properties depend on Mw as well as other parameters.
\end{abstract}

\section{Introduction}

Polyolefins are prepared commercially using different initiator and catalysts like free radical initiators, Phillips type catalysts, and Ziegler-Natta catalysts. Among these, the heterogeneous Ziegler-Natta catalysts remain the main industrial catalysts of choice because of their remarkable ability to affect the polymerization of olefins to produce polymers of high molecular weight and ordered structure $[1,2]$. A unique feature of these catalysts is the presence of more than one active site type which leads to polyolefins with broad molecular weight distributions (MWD) and stereoregularity. These distributions influence the physical properties of polyolefins and are responsible for their performance and final applications. Heterogeneous Ziegler-Natta resins dominate the polyolefin market now and will still be a major fraction of the polyolefin market in the next decade because of their versatility and low cost.

Ziegler-Natta catalysts have been used to synthesize polyethylene and polypropylene [3, 4]. There are two types of Ziegler-Natta catalysts: one is supported type and the other is nonsupported type [5, 6]. Among the supported type Ziegler-Natta catalysts, titanium-magnesium supported Ziegler-Natta catalysts are mostly used to synthesize polyolefins $[7,8]$. The final properties of synthetic polyolefins are affected by different polymerization parameters. There are many literatures where the molecular weight $(\mathrm{Mw})$, molecular weight distribution (MWD), melting temperature, and $\%$ crystallinity of polyolefins are strongly dependent on polymerization parameters like hydrogen pressure, ethylene pressure, polymerization temperature, and polymerization time [9-13]. However, systematic discussions about the 


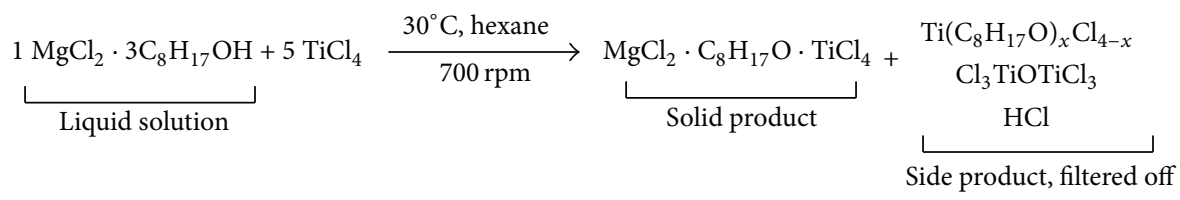

SCHEme 1: Synthesis of the magnesium supported Ziegler-Natta catalyst.

effect of these polymerization parameters on the polyolefins final properties like dynamic mechanical properties, thermal properties, and mechanical properties are really scanty.

The objectives of this study are to produce polyethylene with heterogeneous Ziegler-Natta catalysts in controlled laboratory-scale reactors and correlate the macroscopic properties to polymerization conditions. The effect of different polymerization conditions like hydrogen pressure, ethylene pressure, polymerization temperature, and polymerization time on molecular weight $(\mathrm{Mw})$, molecular weight distribution (MWD), dynamic mechanical properties, thermal properties, and mechanical properties have been studied. Moreover, some correlations of Mw with dynamic mechanical, thermal, and tensile properties has been made and their fittings have been discussed.

\section{Materials, Methods, and Experimental Techniques}

2.1. Materials. All operations were performed under ultrahigh purity nitrogen (99.999\%, purchased from Praxair) using standard Schlenk techniques or inside the glove box. Polymer grade ethylene (99.9\%, purchased from Praxair) and ultrahigh purity nitrogen were purified by passing through columns packed with R3-11 copper catalyst, activated alumina, and 3A/4A mixed molecular sieves. Materials for catalyst synthesis such as magnesium chloride $\left(\mathrm{MgCl}_{2}\right.$, power325 mesh) and titanium (IV) chloride $\left(\mathrm{TiCl}_{4}, 99 \%\right)$ were purchased from Aldrich and 2-ethyl-1-hexanol (99\%) was procured from Alfa Aesar. These materials were used without further purification. The activator, triethyl aluminium (TEA, $1 \mathrm{M}$ in hexane), was purchased from Aldrich. The reaction diluent, hexane (HPLC grade, 95\% n-hexane), used for synthesis of the catalyst and polymerization, was purchased from J. T. Baker and purified by passing through columns packed with activated alumina and molecular sieves (Zeolum Type F-9, Tosoh Co.). Purified solvent was stored in Schlenk flasks with 3A/4A mixed molecular sieves.

\subsection{Synthesis of Magnesium Supported Ziegler-Natta Catalyst.} The catalyst preparation has been carried out through a typical procedure mentioned in the literature [14]. In this method, magnesium chloride (7.62 g, $0.08 \mathrm{~mol})$, 2-ethyl-1hexanol (37.5 mL, $0.24 \mathrm{~mol})$, and $200 \mathrm{~mL}$ hexane as solvent were added to a $500 \mathrm{~mL}$ round flask. The mixture was stirred and refluxed for 24 hours, and then a clear solution was obtained. $0.5 \mathrm{~mol}$ of titanium (IV) chloride was slowly added drop wise at $30^{\circ} \mathrm{C}$ under a stirring rate of $700 \mathrm{rpm}$, and the mixture was additionally reacted for 2 hours. The precipitated product was filtered, washed three times with hexane, and then dried under nitrogen flow. A dried white powder was isolated at the end of the reaction. The synthetic route for the catalyst synthesis is shown in Scheme 1.

2.3. Ethylene Polymerization. Ethylene polymerizations using the magnesium supported Ziegler-Natta catalyst were conducted under various reaction conditions. Polymerizations were carried out in a $300 \mathrm{~mL}$ semibatch autoclave reactor equipped with a mass flow meter and a temperature control unit consisting of a cooling coil and an electric heater. The polymerization temperature was maintained within $\pm 0.2^{\circ} \mathrm{C}$ of the set point. Prior to each reaction, the reactor was purged five times with nitrogen, then heated to $140^{\circ} \mathrm{C}$ under vacuum, and purged again to the set point temperature under nitrogen flow. A volume of $200 \mathrm{~mL}$ solvent and the triethyl aluminium activator were transferred to the reactor and stirred for 5 minutes. The amount of triethyl aluminium was fixed at $2.0 \mathrm{mmol}$. Catalyst slurry with hexane was injected into the reactor and stirred for 10 minutes. The polymerization was performed with a continuous ethylene flow to meet the desired ethylene pressure under a stirring rate of $500 \mathrm{rpm}$. At the end of polymerization time, the reactor was rapidly vented and the obtained polymer was precipitated in $200 \mathrm{~mL}$ ethanol and then filtered and dried under vacuum.

2.4. Gel Permeation Chromatography (GPC). Molecular weight and molecular weight distribution were determined by gel permeation chromatography (GPC-IR, Polymer Char). Samples were dissolved at $160^{\circ} \mathrm{C}$ in 1,2,4-trichlorobenzene and passed through three linear Polymer Laboratories columns which were calibrated with polystyrene standards and operated with a flow rate of $1 \mathrm{~mL} / \mathrm{min}$. Details of GPC and NMR characterization procedure have been reported elsewhere [15].

2.5. Differential Scanning Calorimetry (DSC). The melting temperature of the polymer was determined using differential scanning calorimetry (DSC, TA Instruments DSC 2920). Two scans were performed. The first melting scan was used to erase the thermal history of the sample, followed by cooling with air. The second scan was done at a heating rate of $10^{\circ} \mathrm{C} / \mathrm{min}$ and used to characterize the sample.

2.6. Dynamic Mechanical Analysis (DMA). Dynamic mechanical analysis is a method that measures the stiffness and mechanical damping (i.e., storage and loss moduli in the solid state) of a cyclically deformed material as a function of temperature, strain, and frequency. The combination of stiffness and damping properties is a reflection of the unique viscoelastic nature of polymers. The Q800 DMA from TA 
TABLE 1: Ethylene polymerization using Ziegler-Natta catalyst.

\begin{tabular}{|c|c|c|c|c|c|c|c|c|c|c|}
\hline \multirow[b]{2}{*}{ S/no. } & \multicolumn{5}{|c|}{ Polymerization } & \multicolumn{5}{|c|}{ Results } \\
\hline & $\begin{array}{c}\text { Catalyst } \\
\text { (mg) }\end{array}$ & $\begin{array}{c}P_{\mathrm{C}_{2}} \\
\text { (atm) }\end{array}$ & $\begin{array}{c}P_{\mathrm{H}_{2}} \\
\text { (atm) }\end{array}$ & $\begin{array}{l}\text { Temp. } \\
\left({ }^{\circ} \mathrm{C}\right)\end{array}$ & $\begin{array}{l}\text { Time } \\
\text { (hour) }\end{array}$ & $\begin{array}{l}\text { Yield } \\
(\mathrm{g})\end{array}$ & $\begin{array}{c}\text { Activity } \\
(\mathrm{kg} \text { PE/G cat } \cdot \mathrm{h})\end{array}$ & $\begin{array}{c}\mathrm{Mn} \\
(\mathrm{kg} / \mathrm{mol})\end{array}$ & $\begin{array}{c}\text { Mw } \\
(\mathrm{kg} / \mathrm{mol})\end{array}$ & $\begin{array}{c}\text { PDI } \\
\text { Mw/Mn }\end{array}$ \\
\hline 1 & 3.0 & 5 & 0 & 60 & 0.5 & 9.0 & 8.3 & 88 & 325 & 3.69 \\
\hline 2 & 3.1 & 5 & 0 & 60 & 1 & 20.1 & 6.5 & 83 & 340 & 4.10 \\
\hline 3 & 3.4 & 5 & 0 & 80 & 0.5 & 8.3 & 4.9 & 78 & 310 & 3.97 \\
\hline 4 & 3.4 & 5 & 0 & 80 & 1 & 9.6 & 2.8 & 80 & 317 & 3.96 \\
\hline 5 & 2.9 & 5 & 2 & 60 & 0.5 & 8.1 & 6.6 & 30 & 111 & 3.70 \\
\hline 6 & 3.0 & 5 & 2 & 60 & 1 & 17.4 & 5.8 & 25 & 112 & 4.48 \\
\hline 7 & 3.0 & 5 & 2 & 80 & 0.5 & 4.8 & 3.2 & 19 & 89 & 4.68 \\
\hline 8 & 3.0 & 5 & 2 & 80 & 1 & 7.8 & 2.6 & 23 & 102 & 4.43 \\
\hline 9 & 3.0 & 5 & 5 & 60 & 0.5 & 4.9 & 3.3 & 19 & 103 & 5.42 \\
\hline 10 & 3.0 & 5 & 5 & 60 & 1 & 7.7 & 2.6 & 14 & 92 & 6.57 \\
\hline 11 & 3.3 & 5 & 5 & 80 & 0.5 & 3.1 & 1.9 & 10 & 57 & 5.70 \\
\hline 12 & 3.0 & 5 & 5 & 80 & 1 & 3.5 & 1.0 & 12 & 66 & 5.50 \\
\hline 13 & 3.4 & 10 & 0 & 60 & 0.5 & 38.5 & 22.6 & 167 & 662 & 3.96 \\
\hline 14 & 3.5 & 10 & 0 & 60 & 1 & 45.8 & 13.1 & 158 & 655 & 4.15 \\
\hline 15 & 3.3 & 10 & 0 & 80 & 0.5 & 26.5 & 16.1 & 162 & 617 & 3.81 \\
\hline 16 & 3.1 & 10 & 0 & 80 & 1 & 28.5 & 9.2 & 154 & 625 & 4.06 \\
\hline 17 & 3.3 & 10 & 2 & 60 & 0.5 & 23.9 & 14.5 & 35 & 176 & 5.03 \\
\hline 18 & 3.3 & 10 & 2 & 60 & 1 & 43.6 & 13.2 & 30 & 161 & 5.37 \\
\hline 19 & 3.1 & 10 & 2 & 80 & 0.5 & 22.9 & 14.8 & 25 & 127 & 5.08 \\
\hline 20 & 3.2 & 10 & 2 & 80 & 1 & 39.1 & 12.2 & 68 & 267 & 3.93 \\
\hline 21 & 3.0 & 10 & 5 & 60 & 0.5 & 20.2 & 13.5 & 40 & 226 & 5.65 \\
\hline 22 & 3.2 & 10 & 5 & 60 & 1 & 32.1 & 10.3 & 49 & 239 & 4.88 \\
\hline 23 & 3.0 & 10 & 5 & 80 & 0.5 & 15.4 & 10.3 & 39 & 169 & 4.33 \\
\hline 24 & 3.2 & 10 & 5 & 80 & 1 & 25.1 & 7.8 & 41 & 178 & 4.34 \\
\hline
\end{tabular}

Instruments was used to get the dynamic mechanical properties of the polymer samples. Single cantilever of $8 \mathrm{~mm}$ length fixture was used to run the DMA tests. The sample specimens were prepared in carver press using the fixed size mold. The specimen dimension was $8 \mathrm{~mm}$ length, $10.1 \mathrm{~mm}$ width, and a thickness between 0.65 and $0.75 \mathrm{~mm}$. Temperature step frequency sweep test was run in strain controlled mode. The frequency range was $0.1-100 \mathrm{~Hz}$ and the strain was 15 micron. The temperature was varied in the range $40-80^{\circ} \mathrm{C}$ with a step of $10^{\circ} \mathrm{C}$ per each frequency sweep. The experimental data were then exported in time temperature superposition (TTS) mode to get the flow activation energy.

2.7. Mechanical Testing. The sample specimen for mechanical test was prepared using a dog-bone mold in carver press. The specimen used for the tensile tests was prepared according to ASTM D638 (Type V). The tensile tests were performed using an Instron 5567 tensile testing machine at room temperature. The gauge length was kept at $25 \mathrm{~mm}$ with a crosshead speed of $50 \mathrm{~mm} / \mathrm{min}$.

\section{Results and Discussion}

3.1. Effect of Polymerization Conditions on Molecular Weight $(M w)$ and Molecular Weight Distribution (MWD) of Polyethylenes. The effects of polymerization conditions on $\mathrm{Mw}$ and MWD of polyethylenes have been presented in Table 1. The effect of hydrogen pressure $(0,2$, and 5 bar $)$ on $\mathrm{Mw}$ and MWD has been reported at two different ethylene pressures (5 and 10 bar), polymerization temperatures (60 and $80^{\circ} \mathrm{C}$ ), and polymerization times ( 30 and $60 \mathrm{~min}$ ). As the hydrogen pressure is increased, while maintaining a constant polymerization temperature $\left(60\right.$ or $\left.80^{\circ} \mathrm{C}\right)$, polymerization time (30 or $60 \mathrm{~min}$ ), and ethylene pressure ( 5 or $10 \mathrm{bar}$ ), it is observed that the Mw of polyethylene decreases, whereas the MWD (PDI) increases. It has been mentioned in the literature that hydrogen acts as an efficient chain transfer agent [9, 10]. Thus, an increase in hydrogen pressure leads to the termination of the polymerization reaction resulting in the lowering of molecular weight and broadening of molecular weight distribution. Our observation is in good agreement with the findings made by Moballegh and Hakim [10], where the effect of hydrogen pressure on $\mathrm{Mw}$ and MWD has been reported for ethylene/1-butene copolymer [10]. Both the polymer yield and catalyst activity decrease with the increase in hydrogen pressure. As mentioned earlier, hydrogen acts as chain transfer agent for the reaction; thus, an increase in hydrogen pressure leads to an increase in its concentration at the catalyst active sites. This results in a decrease in the availability of ethylene at the active catalyst sites and favours the termination of polymerization reaction. Hence, both the polymer yield and catalyst activity are reduced. 
The impact of ethylene pressure ( 5 and 10 bar) on Mw and MWD has been reported at three different hydrogen pressures $(0,2$, and 5 bar), two polymerization temperature (60 and $80^{\circ} \mathrm{C}$ ), and two polymerization times (30 and $60 \mathrm{~min}$ ), as can be seen from Table 1. It is seen that with the increase in ethylene pressure from 5 to $10 \mathrm{bar}$, an increase in molecular weight is observed. This result is found to be similar with previous investigations [9], where an increase in molecular weight was reported. The effect of ethylene pressure on MWD is not systematic. It has been mentioned in the literature that the monomer ethylene acts as an activator for the catalyst for the polymerization reaction [9]. Hence, with the increase in ethylene pressure, an increase in $\mathrm{Mw}$ is observed. The increase in ethylene pressure leads to the improvement in polymer yield and catalyst activity as observed in Table 1 . The increase in ethylene pressure increases its availability at the active catalyst sites. Thus, catalyst activity increases which improves the polymer yield.

The polymerization temperature also effects the Mw of polyethylene homopolymers. It is observed from Table 1 that the increase in polymerization temperature from 60 to $80^{\circ} \mathrm{C}$, there is the decrease in $\mathrm{Mw}$ of the resulting polymer when ethylene pressure is maintained at both 5 and 10 bar. This decrease in Mw at higher polymerization temperature is due to stronger chain transfer reaction during polymerization. The MWD (PDI) of ethylene homopolymers are not in proper order with polymerization temperature. It is seen from the table that both the polymer yield and catalyst activity decrease with the increase in polymerization temperature.

The results in Table 1 show that the increase in reaction time from 30 min to 1 hour has less impact on Mw and MWD (PDI), when the experiments are carried out at 5-bar ethylene pressure. In this case, the Mw and MWD (PDI) are irregular in nature. The irregularity in the effect of reaction time on Mw is also observed when the experiments are carried out at 10 -bar ethylene pressure. These results are in agreement with the findings reported elsewhere [11]. However, the increase in polymerization time improves the polymer yield but reduces the catalyst activity as observed in Table 1 . The reason is that the monomers get more time for the formation of polymer; hence, polymer yield increases. As the time increases, the concentration of ethylene monomer at the catalyst active sites decreases. Hence, the catalyst activity is reduced.

3.2. Dynamic Mechanical Analysis (DMA). Dynamic temperature step/frequency sweep tests produce solid state dynamic mechanical properties of polymeric samples as a function of both temperature and frequency. Figure 1 shows the variation of storage modulus $\left(G^{\prime}\right)$ with respect to frequency at different temperature for sample 5 that is at hydrogen pressure $=$ 2 bar, ethylene pressure $=5$ bar, polymerization temperature $(T)=60^{\circ} \mathrm{C}$, and polymerization time $(t)=30 \mathrm{~min}$. It is observed from this figure that the increase in frequency increases the $G^{\prime}$ of the polymer almost linearly. However, the progressive increase in temperature leads to the decrease in storage modulus. Actually, the molecular motion in polymer changes with the increase in temperature. This makes the polymer sample softer, which results in lowering of storage energy. The $\tan \delta$ versus frequency plots for sample 5 has been

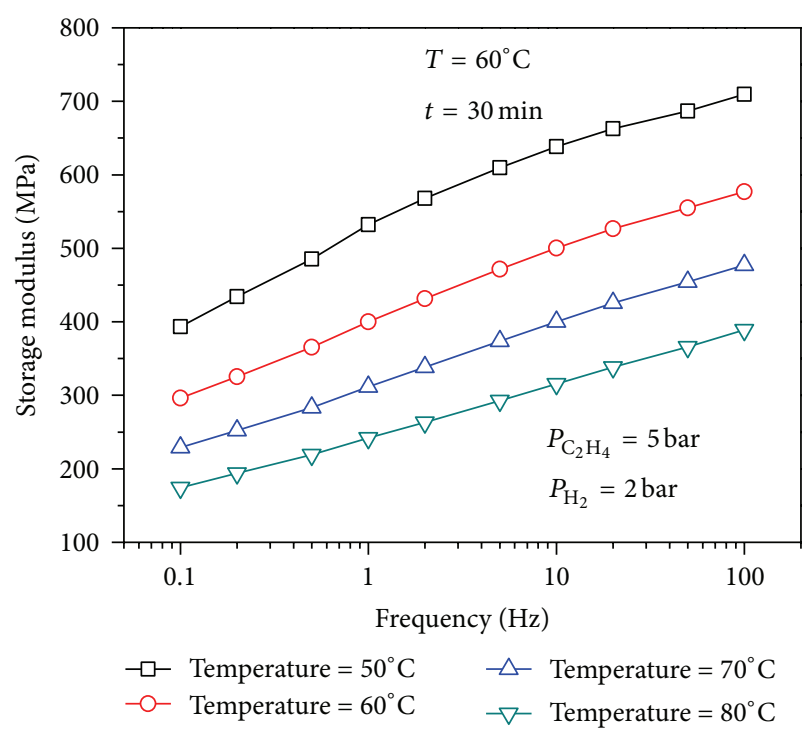

FIGURE 1: Dynamic temperature step/frequency sweep for polyethylene sample 5 synthesized at $P_{\mathrm{C}_{2} \mathrm{H}_{4}}=5 \mathrm{bar}, P_{\mathrm{H}_{2}}=2 \mathrm{bar}, T_{\text {polymerization }}$ temperature $=60^{\circ} \mathrm{C}$, and $t_{\text {polymerization }}$ time $=30 \mathrm{~min}$.

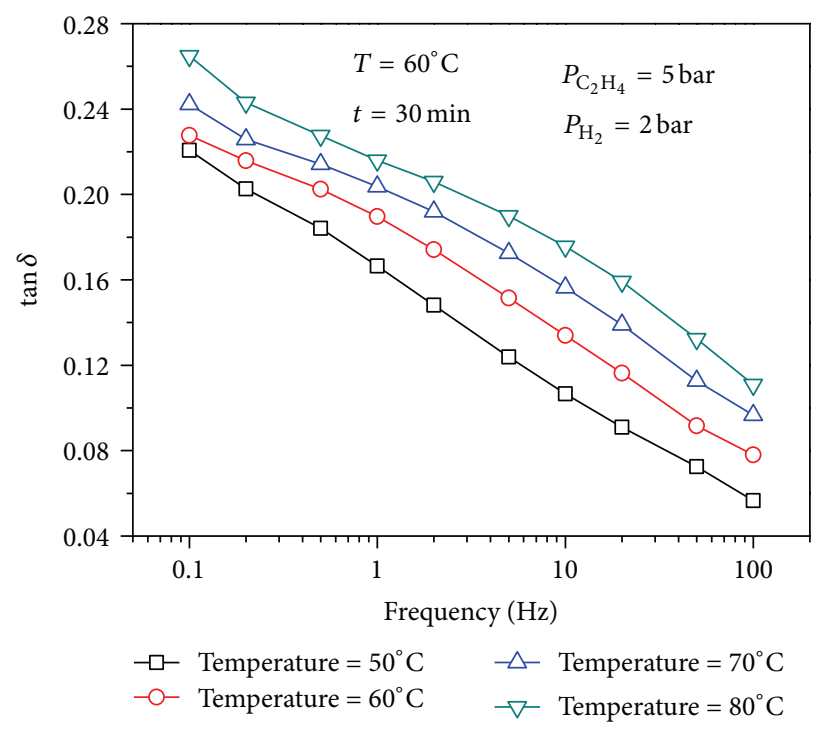

Figure 2: Dynamic temperature step/frequency sweep $(\tan \delta)$ for polyethylene sample 5 synthesized at $P_{\mathrm{C}_{2} \mathrm{H}_{4}}=5 \mathrm{bar}, P_{\mathrm{H}_{2}}=2 \mathrm{bar}$, $T_{\text {polymerization }}$ temperature $=60^{\circ} \mathrm{C}$, and $t_{\text {polymerization }}$ time $=30 \mathrm{~min}$.

presented in Figure 2, which shows the decrease in $\tan \delta$ with the increase in frequency. On the contrary, $\tan \delta$ increases with the increase in temperature. This increase in $\tan \delta$ is due to the decrease in $G^{\prime}$ of the sample with the increase in temperature.

Figure 3 shows the effect of frequency on $G^{\prime}$ at hydrogen pressure $(0,2$, and 5 bar) for samples 1,5 , and 9 , that is, at ethylene pressure $=5$ bar, polymerization temperature $=$ $60^{\circ} \mathrm{C}$, and polymerization time $=30 \mathrm{~min}$, where the measurement temperature was maintained at $60^{\circ} \mathrm{C}$. It is seen from the figure that the increase in hydrogen pressure reduces the $G^{\prime}$. It 


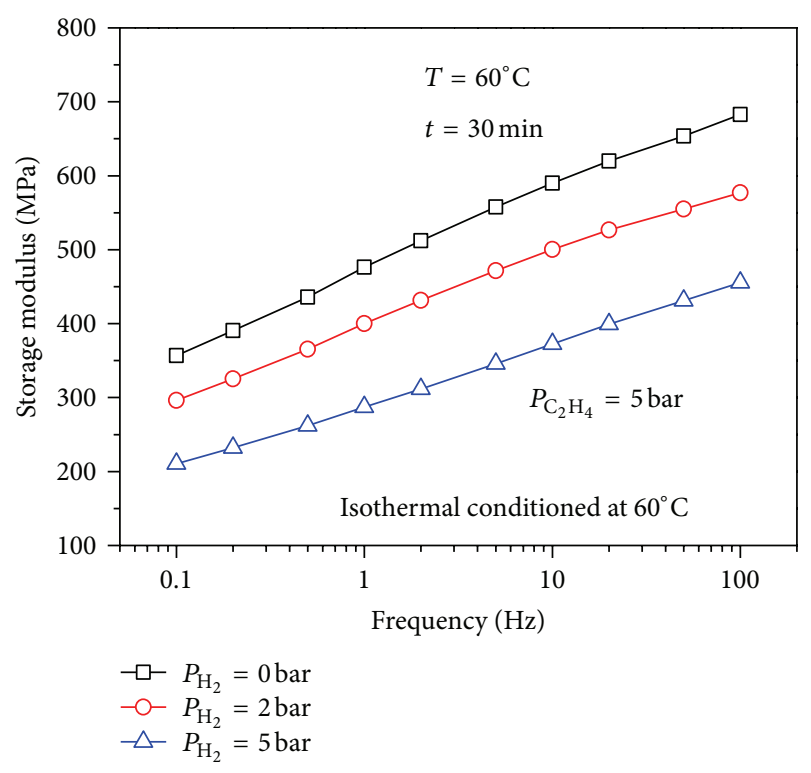

FIGURE 3: Storage modulus of polyethylene synthesized at $P_{\mathrm{C}_{2} \mathrm{H}_{4}}=$ 5 bar, $T_{\text {polymerization }}$ temperature $=60^{\circ} \mathrm{C}$, and $t_{\text {polymerization }}$ time $=30$ minutes (samples 1, 5, and 9).

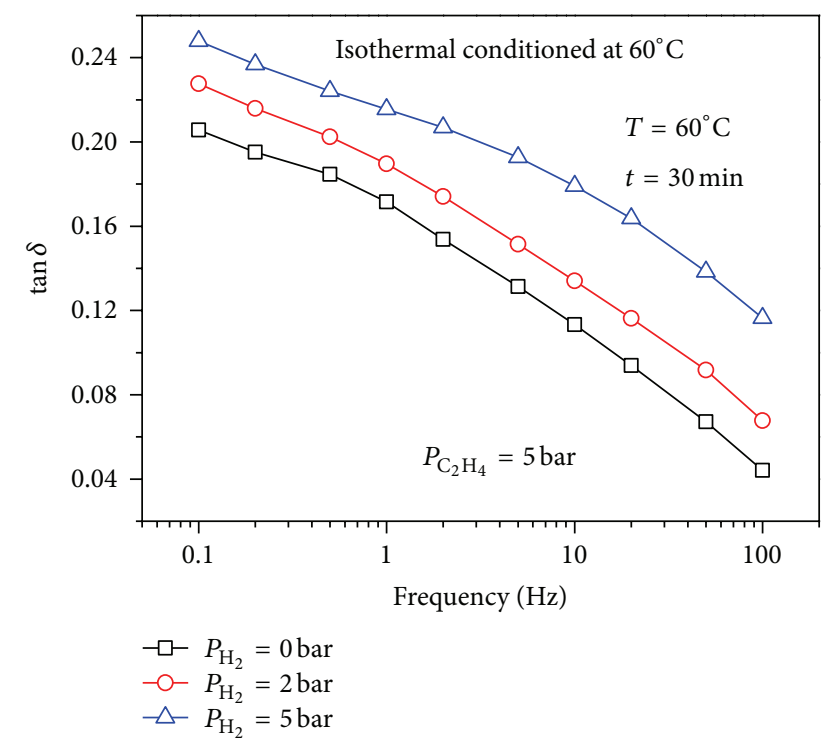

FIgURE 4: $\tan \delta$ of polyethylene synthesized at $P_{\mathrm{C}_{2} \mathrm{H}_{4}}=5 \mathrm{bar}$, $T_{\text {polymerization }}$ temperature $=60^{\circ} \mathrm{C}$, and $t_{\text {polymerization }}$ time $=30$ minutes (samples 1, 5, and 9).

has been mentioned earlier that hydrogen acts as an efficient chain transfer agent for the reaction. Thus, the incorporation of hydrogen leads to the formation of polymer with short chain length. This results in lowering the molecular weight and consequently reducing storage modulus. $\tan \delta$ versus frequency plots at different hydrogen pressure for the samples 1,5 , and 9 has been shown in Figure 4. It is found that the $\tan \delta$ value increases with the increase in hydrogen pressure at all frequency ranges. Actually, the molecular movement in low Mw polymer is higher compared to high molecular weight polymer. As $\tan \delta$ (damping factor) is a measure of molecular movement (structural transformation) in polymer, hence, the increase in molecular movement in polymer will result in a higher value of $\tan \delta$. This is why the low molecular weight polymer (short chain length polymer) will have higher value of $\tan \delta$ compared to the polymer with a long chain. The trends in variation in the effects of ethylene pressure and polymerization temperature on storage modulus and $\tan \delta$ of the polymer have been found almost similar (not shown in the figure), the only difference is in their magnitude. A correlation of Mw with $G^{\prime}$ and $\tan \delta$ has been established and shown in Figures 5(a) and 5(b). It is seen from the figure that $G^{\prime}$ increases but $\tan \delta$ decreases with the increase in Mw. The coefficients of correlation $\left(R^{2}\right)$ of linear fit for $G^{\prime}$ and $\tan \delta$ are 0.90 and 0.89 , respectively, a little bit away from unity. This indicates that $G^{\prime}$ and $\tan \delta$ also depend on other parameters like polymer crystallinity.

The activation energy $(\Delta E)$ for all the samples has been extracted from the DMA data using the time temperature superposition technique (TTS). The results are presented in Table 2. It is found that the $\Delta E$ for all samples is in the range $198.3 \pm 4.3-294.2 \pm 5.7 \mathrm{~kJ} / \mathrm{mol} . \Delta E$ is found to increase with the increase in ethylene pressure but decrease with the increase in hydrogen pressure and polymerization temperature. The relation between $\Delta E$ and $\mathrm{Mw}$ has been presented in Figure 5(c). The samples with higher Mw exhibit high values of $\Delta E$. The value of $R^{2}$ is 0.93 . This suggests that the similarity of the structure resulted in similar values for $\Delta E$.

3.3. Differential Scanning Calorimeter (DSC). The results of crystallization temperature $\left(T_{c}\right)$, melting temperature $\left(T_{m}\right)$, and $\%$ crystallinity $\left(\% X_{c}\right)$ have been extracted from the DSC experiments and are presented in Table 3 for the polyethylene samples. It is observed from the table that the $T_{c}$ of polyethylenes is not affected so much by polymerization parameters; that is, the $T_{c}$ remains in between $117.37 \pm$ $1.43-119.98 \pm 2.18^{\circ} \mathrm{C}$. However, there is impact of polymerization parameters on $T_{m}$ and \% crystallinity.

It is seen from the table that the increase in hydrogen pressure decreases the melting point due to the decrease in Mw. A polymer with lower Mw will have lower surface area, that means lower physical attraction between the polymer chains and low $T_{m}$ [16]. On the other hand, melting point is slightly increased with the increase in ethylene pressure. At 5-bar ethylene pressure, the $T_{m}$ is in between $141.54 \pm$ $1.59-134.5 \pm 1.86^{\circ} \mathrm{C}$, whereas, at 10 -bar ethylene pressure, the range is $142.93 \pm 2.08-135.87 \pm 2.15^{\circ} \mathrm{C}$. With the increase in polymerization temperature, the $T_{m}$ of polyethylene is found to decrease slightly. This is likely due to the decrease in $\mathrm{Mw}$ with the increase in polymerization temperature as shown in Table 1 . However, the polymerization time has no effect on $T_{m}$ of the polyethylene homopolymer.

The effect of hydrogen pressure on polymer crystallinity has also been reported in Table 3. It is seen that the increase in hydrogen pressure increases the crystallinity of the polymer. In coordination polymerization, successive polymerization and crystallization take place [12]. The increase in hydrogen pressure blocks the active sites of polymerization because hydrogen acts as chain transfer agent for the reaction. Thus, 


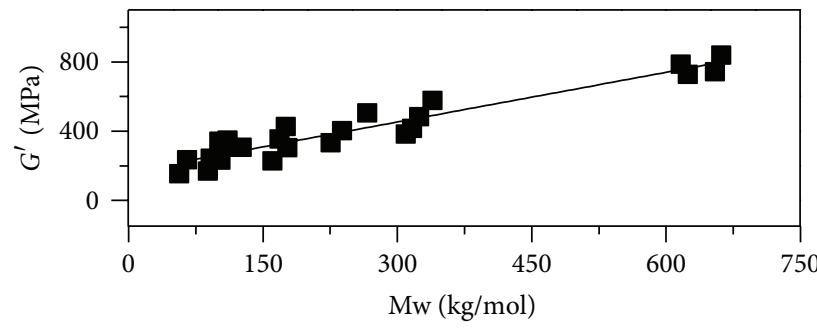

$R^{2}=0.90$

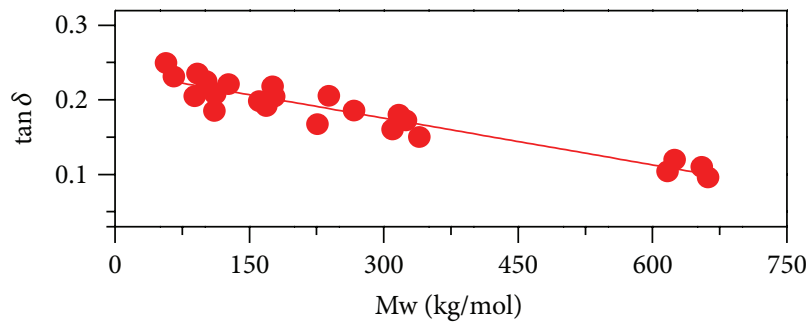

$R^{2}=0.89$

(a)

(b)

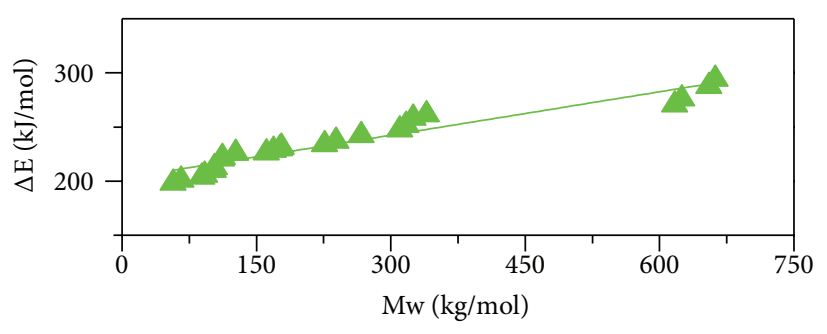

$\triangle R^{2}=0.93$

(c)

Figure 5: Correlation of Mw with (a) $G^{\prime}$, (b) $\tan \delta$, and (c) $\Delta E$.

TABLE 2: Activation energy for polyethylene samples.

\begin{tabular}{|c|c|c|c|c|c|c|}
\hline Sample & $\begin{array}{r}P_{\mathrm{C}_{2} \mathrm{H}_{4}} \\
\text { (bar) }\end{array}$ & $\begin{array}{l}P_{\mathrm{H}_{2}} \\
\text { (bar) }\end{array}$ & $\begin{array}{l}\text { Temp. } \\
\left({ }^{\circ} \mathrm{C}\right)\end{array}$ & $\begin{array}{l}\text { Time } \\
\text { (hour) }\end{array}$ & $\begin{array}{c}\text { Mw } \\
(\mathrm{kg} / \mathrm{mol})\end{array}$ & $\begin{array}{c}\text { Activation energy, } \Delta E \\
(\mathrm{~kJ} / \mathrm{mol})\end{array}$ \\
\hline 1 & 5 & 0 & 60 & 0.5 & 325 & $258.1 \pm 6.3$ \\
\hline 2 & 5 & 0 & 60 & 1 & 340 & $261.4 \pm 8.5$ \\
\hline 3 & 5 & 0 & 80 & 0.5 & 310 & $247.5 \pm 8.5$ \\
\hline 4 & 5 & 0 & 80 & 1 & 317 & $251.6 \pm 9.4$ \\
\hline 5 & 5 & 2 & 60 & 0.5 & 111 & $220.6 \pm 4.9$ \\
\hline 6 & 5 & 2 & 60 & 1 & 112 & $221.9 \pm 9.5$ \\
\hline 7 & 5 & 2 & 80 & 0.5 & 89 & $203.8 \pm 5.6$ \\
\hline 8 & 5 & 2 & 80 & 1 & 102 & $210.2 \pm 6.9$ \\
\hline 9 & 5 & 5 & 60 & 0.5 & 103 & $212.5 \pm 7.4$ \\
\hline 10 & 5 & 5 & 60 & 1 & 92 & $205.6 \pm 7.8$ \\
\hline 11 & 5 & 5 & 80 & 0.5 & 57 & $198.3 \pm 4.3$ \\
\hline 12 & 5 & 5 & 80 & 1 & 66 & $200.8 \pm 5.2$ \\
\hline 13 & 10 & 0 & 60 & 0.5 & 662 & $294.2 \pm 5.7$ \\
\hline 14 & 10 & 0 & 60 & 1 & 655 & $287.6 \pm 3.2$ \\
\hline 15 & 10 & 0 & 80 & 0.5 & 617 & $270.4 \pm 8.7$ \\
\hline 16 & 10 & 0 & 80 & 1 & 625 & $275.9 \pm 5.4$ \\
\hline 17 & 10 & 2 & 60 & 0.5 & 176 & $229.8 \pm 6.4$ \\
\hline 18 & 10 & 2 & 60 & 1 & 161 & $226.1 \pm 5.6$ \\
\hline 19 & 10 & 2 & 80 & 0.5 & 127 & $225.7 \pm 9.5$ \\
\hline 20 & 10 & 2 & 80 & 1 & 267 & $242.3 \pm 5.7$ \\
\hline 21 & 10 & 5 & 60 & 0.5 & 226 & $233.7 \pm 4.9$ \\
\hline 22 & 10 & 5 & 60 & 1 & 239 & $236.9 \pm 4.6$ \\
\hline 23 & 10 & 5 & 80 & 0.5 & 169 & $228.7 \pm 6.8$ \\
\hline 24 & 10 & 5 & 80 & 1 & 178 & $231.3 \pm 4.3$ \\
\hline
\end{tabular}


TABLE 3: DSC analysis for polyethylene samples.

\begin{tabular}{|c|c|c|c|c|c|c|c|}
\hline Sample & $\begin{array}{l}P_{\mathrm{C}_{2} \mathrm{H}_{4}} \\
\text { (bar) }\end{array}$ & $\begin{array}{c}P_{\mathrm{H}_{2}} \\
\text { (bar) }\end{array}$ & $\begin{array}{c}\text { Temp. } \\
\left({ }^{\circ} \mathrm{C}\right)\end{array}$ & $\begin{array}{l}\text { Time } \\
\text { (hour) }\end{array}$ & $\begin{array}{c}T_{c} \\
\left({ }^{\circ} \mathrm{C}\right)\end{array}$ & $\begin{array}{l}T_{m} \\
\left({ }^{\circ} \mathrm{C}\right)\end{array}$ & $\begin{array}{c}\text { \% crystallinity } \\
\text { (Cooling) }\end{array}$ \\
\hline 1 & 5 & 0 & 60 & 0.5 & $119.01 \pm 2.36$ & $141.54 \pm 1.59$ & $52.00 \pm 2.12$ \\
\hline 2 & 5 & 0 & 60 & 1 & $119.55 \pm 2.48$ & $141.05 \pm 1.85$ & $52.20 \pm 3.22$ \\
\hline 3 & 5 & 0 & 80 & 0.5 & $119.35 \pm 1.98$ & $139.45 \pm 1.64$ & $56.58 \pm 2.42$ \\
\hline 4 & 5 & 0 & 80 & 1 & $119.66 \pm 2.52$ & $139.86 \pm 2.11$ & $54.07 \pm 2.35$ \\
\hline 5 & 5 & 2 & 60 & 0.5 & $118.70 \pm 2.33$ & $138.25 \pm 2.63$ & $57.39 \pm 2.41$ \\
\hline 6 & 5 & 2 & 60 & 1 & $119.98 \pm 2.18$ & $137.13 \pm 1.98$ & $64.03 \pm 2.63$ \\
\hline 7 & 5 & 2 & 80 & 0.5 & $118.5 \pm 2.43$ & $135.18 \pm 1.76$ & $65.53 \pm 3.32$ \\
\hline 8 & 5 & 2 & 80 & 1 & $119.38 \pm 1.78$ & $134.79 \pm 2.42$ & $66.56 \pm 2.96$ \\
\hline 9 & 5 & 5 & 60 & 0.5 & $118.62 \pm 2.15$ & $135.31 \pm 2.31$ & $70.49 \pm 2.85$ \\
\hline 10 & 5 & 5 & 60 & 1 & $119.39 \pm 2.63$ & $134.85 \pm 2.52$ & $68.99 \pm 2.34$ \\
\hline 11 & 5 & 5 & 80 & 0.5 & $119.40 \pm 2.45$ & $134.50 \pm 1.86$ & $76.74 \pm 2.81$ \\
\hline 12 & 5 & 5 & 80 & 1 & $118.10 \pm 1.99$ & $134.73 \pm 1.98$ & $79.41 \pm 3.24$ \\
\hline 13 & 10 & 0 & 60 & 0.5 & $117.72 \pm 1.67$ & $142.93 \pm 2.08$ & $61.05 \pm 2.56$ \\
\hline 14 & 10 & 0 & 60 & 1 & $117.37 \pm 1.43$ & $142.71 \pm 2.36$ & $57.29 \pm 3.65$ \\
\hline 15 & 10 & 0 & 80 & 0.5 & $118.59 \pm 2.86$ & $140.31 \pm 1.22$ & $67.83 \pm 2.42$ \\
\hline 16 & 10 & 0 & 80 & 1 & $118.67 \pm 1.76$ & $140.24 \pm 1.78$ & $67.63 \pm 1.95$ \\
\hline 17 & 10 & 2 & 60 & 0.5 & $118.92 \pm 2.41$ & $139.10 \pm 2.24$ & $74.85 \pm 2.41$ \\
\hline 18 & 10 & 2 & 60 & 1 & $119.35 \pm 2.22$ & $138.81 \pm 2.46$ & $74.88 \pm 2.87$ \\
\hline 19 & 10 & 2 & 80 & 0.5 & $119.12 \pm 2.37$ & $138.39 \pm 2.27$ & $74.90 \pm 3.23$ \\
\hline 20 & 10 & 2 & 80 & 1 & $119.60 \pm 1.95$ & $137.68 \pm 2.36$ & $78.80 \pm 3.39$ \\
\hline 21 & 10 & 5 & 60 & 0.5 & $119.23 \pm 2.13$ & $136.24 \pm 1.58$ & $81.21 \pm 3.75$ \\
\hline 22 & 10 & 5 & 60 & 1 & $119.40 \pm 2.24$ & $137.07 \pm 1.79$ & $82.64 \pm 2.75$ \\
\hline 23 & 10 & 5 & 80 & 0.5 & $119.06 \pm 2.32$ & $136.07 \pm 1.88$ & $81.75 \pm 2.63$ \\
\hline 24 & 10 & 5 & 80 & 1 & $119.45 \pm 1.79$ & $135.87 \pm 2.15$ & $82.84 \pm 3.15$ \\
\hline
\end{tabular}

the polymerization rate is reduced and crystallization rate is increased. This leads to the higher value of crystallinity with the increase in hydrogen pressure [13]. It is also observed from the table that the increase in ethylene pressure from 5 to 10 bar increases the polymer crystallinity. For sample 5 and sample 17, where the polymerization has been carried out at ethylene pressure 5 and 10 bar (constant polymerization conditions are hydrogen pressure $=2 \mathrm{bar}$, polymerization temperature $=60^{\circ} \mathrm{C}$, and polymerization time $=30 \mathrm{~min}$ ), the $\%$ crystallinity is found to be $57.39 \pm 2.41$ and $74.85 \pm 2.41$, respectively. Thus, the increase in crystallinity in this case is around $30 \%$. This increment in crystallinity has been found to vary according to polymerization condition. The increase in crystallinity with the increase in ethylene pressure has also been reported elsewhere though the effect is less significant [11]. In the same table, it can be seen that the increase in polymerization temperature leads to increase in crystallinity. The increase in crystallinity with respect to polymerization temperature at 5-bar ethylene pressure and 0-bar hydrogen pressure (for samples 1 and 3) is around 9\%, whereas, at 5-bar ethylene and hydrogen pressure (samples 9 and 11), the increment in crystallinity is around 23\%. However, at 10-bar ethylene pressure and 5-bar hydrogen pressure (for the sample sets 21 and 23), the effect of polymerization temperature on crystallinity is very marginal. Thus, it can be said that the effect of polymerization temperature on crystallinity is more significant at low ethylene pressure and high hydrogen pressure. The polymerization time has no significant effect on crystallinity as can be seen from the data presented in the same table.

An effort has been made to correlate Mw with polymer properties such as $T_{m}, T_{c}$, and $\% X_{c}$ as shown in Figures 6(a)6(c). It is observed from the figure that $T_{m}$ increases with the increase in Mw but $T_{c}$ and $\% X_{c}$ decrease. The $R^{2}$ of linear fits for $T_{m}, T_{c}$, and $\% X_{c}$ are $0.52,0.49$, and 0.46 , respectively, far away from unity. This suggests that these parameters not only depend on Mw but also on other parameters.

3.4. Mechanical Properties. Mechanical testing results for all the samples have been presented in Table 4 . The results of mechanical testing of polyethylene can be correlated with hydrogen pressure. It is observed from the table that the tensile modulus (TM) of polyethylene increases with the increase in hydrogen pressure. The modulus at 0-bar hydrogen pressure is in the range $454 \pm 22-515 \pm 31 \mathrm{MPa}$, at 2-bar hydrogen pressure is in the range $573 \pm 35-663 \pm$ $29 \mathrm{MPa}$, and at 5-bar hydrogen pressure is in the range $628 \pm$ $31-856 \pm 27 \mathrm{MPa}$ when polymerization is conditioned at 5-bar ethylene pressure. Similarly, when polymerization is conditioned at 10-bar ethylene pressure, the modulus at 0-bar hydrogen pressure is in the range $535 \pm 38-622 \pm 33 \mathrm{MPa}$, at 2-bar hydrogen pressure is in the range $758 \pm 31-879 \pm$ $41 \mathrm{MPa}$, and at 5-bar hydrogen pressure is in the range $873 \pm 38-1019 \pm 51 \mathrm{MPa}$. Thus, the modulus value is higher 
TABLE 4: Results of mechanical testing for polyethylene samples.

\begin{tabular}{|c|c|c|c|c|c|c|c|c|c|}
\hline Sample & $\begin{array}{l}P_{\mathrm{C}_{2} \mathrm{H}_{4}} \\
\text { (bar) }\end{array}$ & $\begin{array}{c}P_{\mathrm{H}_{2}} \\
\text { (bar) }\end{array}$ & $\begin{array}{l}\text { Temp. } \\
\left({ }^{\circ} \mathrm{C}\right)\end{array}$ & $\begin{array}{l}\text { Time } \\
\text { (hour) }\end{array}$ & $\begin{array}{l}\text { Modulus } \\
(\mathrm{MPa})\end{array}$ & $\begin{array}{c}\text { Yield stress } \\
(\mathrm{MPa})\end{array}$ & $\begin{array}{c}\text { Yield strain } \\
(\%)\end{array}$ & $\begin{array}{c}\text { Strain at break } \\
(\%)\end{array}$ & $\begin{array}{c}\text { Tensile strength } \\
(\mathrm{MPa})\end{array}$ \\
\hline 1 & 5 & 0 & 60 & 0.5 & $454 \pm 22$ & $16.32 \pm 1.21$ & 4 & $395 \pm 19$ & $52.08 \pm 6.32$ \\
\hline 2 & 5 & 0 & 60 & 1 & $468 \pm 29$ & $16.38 \pm 1.32$ & 4 & $424 \pm 21$ & $52.79 \pm 4.69$ \\
\hline 3 & 5 & 0 & 80 & 0.5 & $479 \pm 25$ & $16.95 \pm 1.15$ & 4 & $447 \pm 25$ & $51.11 \pm 4.87$ \\
\hline 4 & 5 & 0 & 80 & 1 & $515 \pm 31$ & $16.98 \pm 1.24$ & 4 & $467 \pm 18$ & $51.29 \pm 5.33$ \\
\hline 5 & 5 & 2 & 60 & 0.5 & $573 \pm 35$ & $19.54 \pm 1.36$ & 4 & $433 \pm 23$ & $47.64 \pm 5.41$ \\
\hline 6 & 5 & 2 & 60 & 1 & $549 \pm 28$ & $19.88 \pm 1.28$ & 4 & $491 \pm 27$ & $47.77 \pm 4.84$ \\
\hline 7 & 5 & 2 & 80 & 0.5 & $619 \pm 34$ & $21.87 \pm 1.33$ & 4 & $548 \pm 33$ & $47.37 \pm 4.56$ \\
\hline 8 & 5 & 2 & 80 & 1 & $663 \pm 29$ & $22.15 \pm 1.27$ & 4 & $563 \pm 29$ & $47.57 \pm 4.49$ \\
\hline 9 & 5 & 5 & 60 & 0.5 & $628 \pm 31$ & $23.47 \pm 1.29$ & 4 & $515 \pm 21$ & $47.01 \pm 4.25$ \\
\hline 10 & 5 & 5 & 60 & 1 & $635 \pm 25$ & $24.26 \pm 1.18$ & 4 & $590 \pm 31$ & $46.93 \pm 4.68$ \\
\hline 11 & 5 & 5 & 80 & 0.5 & $832 \pm 29$ & $25.94 \pm 1.37$ & 3 & $639 \pm 35$ & $46.11 \pm 4.31$ \\
\hline 12 & 5 & 5 & 80 & 1 & $856 \pm 27$ & $26.30 \pm 1.23$ & 4 & $669 \pm 24$ & $46.44 \pm 4.11$ \\
\hline 13 & 10 & 0 & 60 & 0.5 & $605 \pm 34$ & $19.38 \pm 1.22$ & 4 & $447 \pm 18$ & $59.81 \pm 6.54$ \\
\hline 14 & 10 & 0 & 60 & 1 & $535 \pm 38$ & $19.64 \pm 1.29$ & 3.6 & $484 \pm 22$ & $59.12 \pm 5.23$ \\
\hline 15 & 10 & 0 & 80 & 0.5 & $622 \pm 33$ & $21.89 \pm 1.19$ & 4.0 & $525 \pm 26$ & $59.14 \pm 4.32$ \\
\hline 16 & 10 & 0 & 80 & 1 & $593 \pm 26$ & $22.18 \pm 1.28$ & 3.8 & $591 \pm 23$ & $58.77 \pm 5.75$ \\
\hline 17 & 10 & 2 & 60 & 0.5 & $758 \pm 31$ & $25.35 \pm 1.30$ & 3.8 & $542 \pm 29$ & $50.70 \pm 5.12$ \\
\hline 18 & 10 & 2 & 60 & 1 & $847 \pm 29$ & $25.49 \pm 1.16$ & 3.7 & $576 \pm 34$ & $48.48 \pm 4.95$ \\
\hline 19 & 10 & 2 & 80 & 0.5 & $789 \pm 37$ & $27.36 \pm 1.12$ & 4 & $593 \pm 38$ & $47.17 \pm 5.46$ \\
\hline 20 & 10 & 2 & 80 & 1 & $879 \pm 41$ & $27.56 \pm 1.31$ & 3 & $632 \pm 27$ & $51.90 \pm 5.63$ \\
\hline 21 & 10 & 5 & 60 & 0.5 & $873 \pm 38$ & $28.32 \pm 1.22$ & 3 & $682 \pm 41$ & $51.06 \pm 6.21$ \\
\hline 22 & 10 & 5 & 60 & 1 & $896 \pm 44$ & $29.29 \pm 1.19$ & 3.5 & $724 \pm 32$ & $50.25 \pm 4.83$ \\
\hline 23 & 10 & 5 & 80 & 0.5 & $1017 \pm 47$ & $30.67 \pm 1.24$ & 3 & $752 \pm 37$ & $47.80 \pm 5.47$ \\
\hline 24 & 10 & 5 & 80 & 1 & $1019 \pm 51$ & $30.77 \pm 1.33$ & 3.5 & $784 \pm 39$ & $48.76 \pm 5.69$ \\
\hline
\end{tabular}

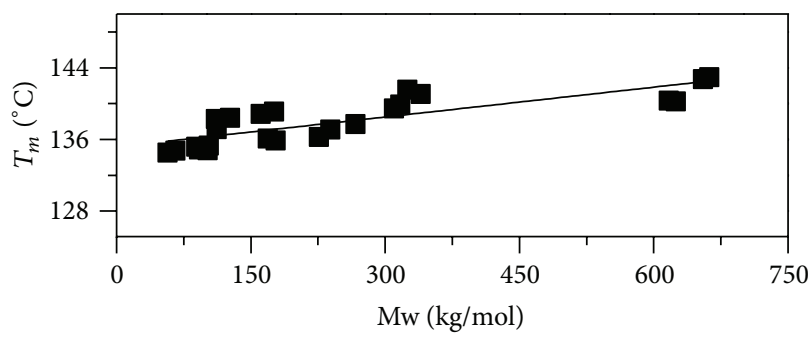

$R^{2}=0.52$

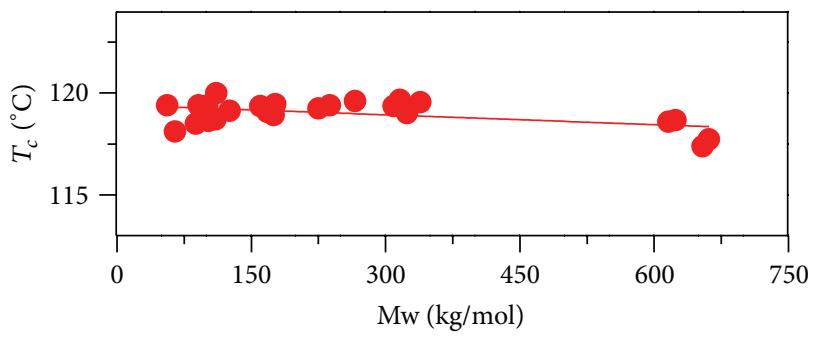

$R^{2}=0.49$

(a)

(b)

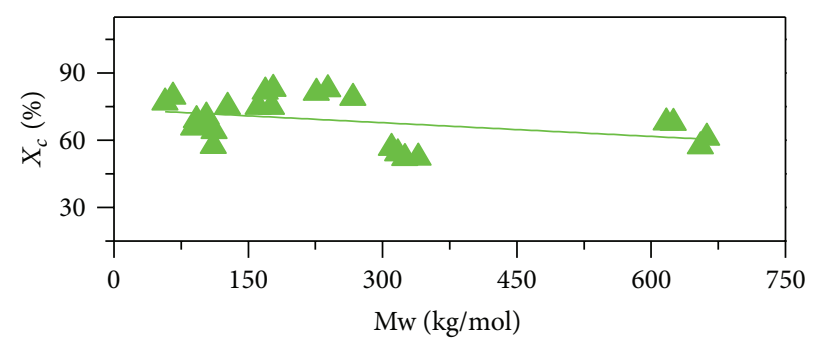

$\triangle R^{2}=0.46$

(c)

Figure 6: Correlation of Mw with (a) $T_{m}$, (b) $T_{c}$, and (c) $X_{c}$. 


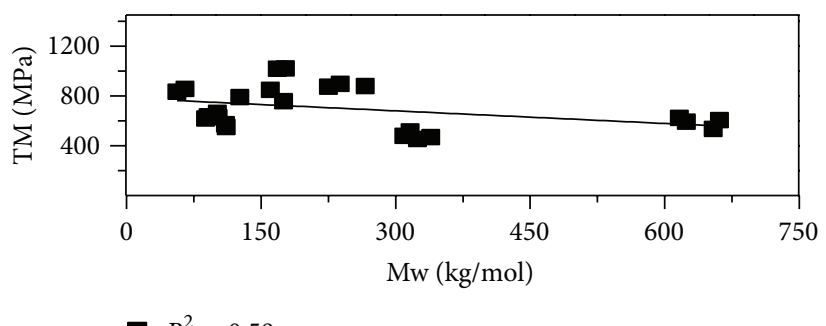

$R^{2}=0.59$

(a)

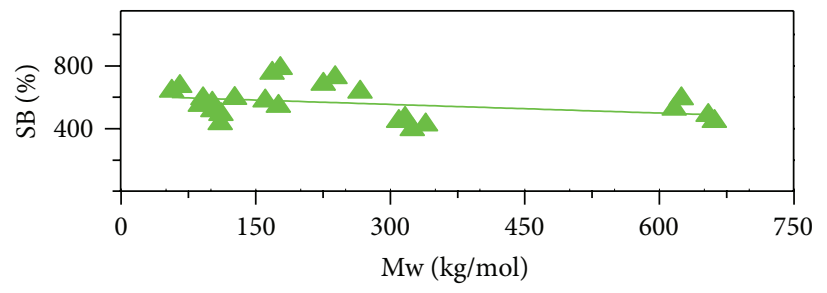

$\triangle R^{2}=0.56$

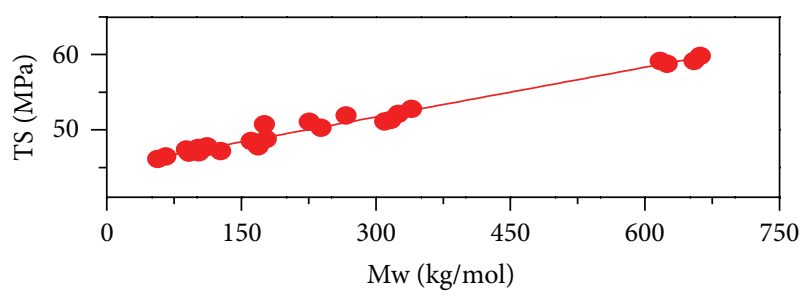

$R^{2}=0.97$

(b)

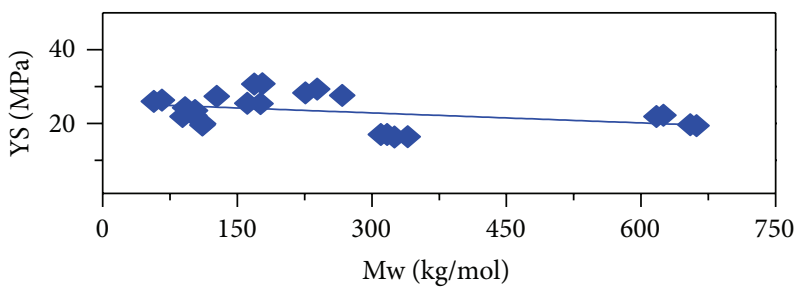

$R^{2}=0.54$

(c)

(d)

FIgure 7: Correlation of Mw with (a) TM, (b) TS, (c) SB, and (d) YS.

when the polymerization is conditioned at higher ethylene pressure. This increase in tensile modulus can be correlated with crystallinity results shown in Table 3 . It is observed that higher crystallinity leads to higher value of tensile modulus.

The effect of hydrogen pressure on \% strain at break (\% $\mathrm{SB})$ has been reported in the same Table 4 . The strain at break (\%) is in between $395 \pm 19-467 \pm 18$ at 0 bar hydrogen pressure (samples 1-4), $433 \pm 23-563 \pm 29$ at 2 bar hydrogen pressure (samples 5-8), and 515 $\pm 21-669 \pm 24$ at 5 bar hydrogen pressure (samples 9-12). Similarly, the strain at break (\%) at 0 bar hydrogen pressure (samples 13-16) is in the range $447 \pm$ $18-591 \pm 23$, at 2 bar hydrogen pressure (samples 17-20) is in the range $542 \pm 29-632 \pm 27$, and at 5 bar hydrogen pressure (samples 21-24) is in the range $682 \pm 41-784 \pm 39$. Thus, there is the increase in strain at break (\%) with the increase in hydrogen and ethylene pressure. The strain at the yield point has remained in the range $3-4 \%$ as seen from the table.

The yield stress (YS) results presented in the table show some variation with hydrogen pressure. It is seen that at 0 bar (samples 1-4), 2 bar (samples 5-8), and 5 bar (samples 912) hydrogen pressure, the yield stress ranges are $16.32 \pm$ $1.21-16.98 \pm 1.24 \mathrm{MPa}, 19.54 \pm 1.36-22.15 \pm 1.27 \mathrm{MPa}$, and $23.47 \pm 1.29-26.30 \pm 1.23 \mathrm{MPa}$, respectively. Thus, an increment in yield stress is observed with the increase in hydrogen pressure. Almost similar type of results is obtained for the sample sets 13-16 (0-bar hydrogen pressure), 17-20 (2bar hydrogen pressure), and 21-24 (5-bar hydrogen pressure). The effect of ethylene pressure on yield stress is less significant compared to hydrogen pressure as is observed from the table. However, the effects of polymerization temperature and time on yield stress are marginal. The tensile strength (TS) results reported in the table show that the strength has improved with the increase in ethylene pressure. But TS decreased with the increase in hydrogen pressure, polymerization temperature, and polymerization time.
The influences of Mw on TM, TS, \% SB, and YS have been shown in Figures $7(\mathrm{a})-7(\mathrm{~d})$. The data points are more random for TM, \% SB, and YS but less random for TS. There is sufficient overall improvement of TS with the increase in Mw. But overall, the other properties decrease with the increase in $\mathrm{Mw}$ and this decrement is marginal. The $R^{2}$ of linear fits for TM, TS, \% SB, and YS are 0.59, 0.97, 0.56, and 0.54 , respectively. The $R^{2}$ value for TS is almost close to unity, whereas for other parameters it is far away from unity. Thus, it can be said that TS is more dependent on Mw compared to other tensile properties. In a similar way, it can be inferred that, other than Mw, these tensile properties also depend on some other parameters like polymer crystallinity, branch chain length, branch chain content, and so forth. Thus, establishment of perfect correlation of these properties with $\mathrm{Mw}$ is really very difficult.

\section{Conclusions}

A decrease in $\mathrm{Mw}$ is observed with the increase in hydrogen pressure and polymerization temperature. The role of hydrogen as chain transfer agent is responsible for this decrease in Mw. There is improvement in Mw with the increase in ethylene pressure. However, the effect of reaction time on $\mathrm{Mw}$ is marginal. The MWD is irregular in nature with the increase in ethylene pressure, polymerization temperature, and reaction time. The storage modulus value decreases but $\tan \delta$ value increases with the increase in polymerization parameters. The activation energy for polyethylenes was in the range $198.3 \pm 4.3-294.2 \pm 5.7 \mathrm{~kJ} / \mathrm{mol}$, regardless of the differences in reaction parameters. The higher the $\mathrm{Mw}$ is, the higher the activation energy is. The increase in reaction temperature, hydrogen pressure, and ethylene pressure leads to increase in polymer crystallinity, tensile modulus, $\%$ elongation at break, and yield stress. The tensile strength has improved 
with the increase in ethylene pressure but reduced with the increase in other polymerization parameters. However, the effect of pressure is more pronounced compared to the reaction temperature. The results for the tensile modulus of polyethylene have been correlated with crystallinity results. The results show that higher crystallinity of polyethylene leads to higher modulus. Overall, strong correlations of the polymerization parameters with thermal and mechanical properties of polyethylene have been observed. The Mw of the polymers has been correlated with their thermal and mechanical properties. The fittings reveal that $\mathrm{Mw}$ influences more $G^{\prime}, \tan \delta, \Delta E$, and TS and less the other thermal $\left(T_{m}\right.$, $T_{c}$, and $\% X_{c}$ ) and mechanical (TM, SB, and YS) properties because these properties are not only influenced by Mw but also depend on other parameters.

\section{Conflict of Interests}

The authors declare that there is no conflict of interests regarding the publication of this paper.

\section{Acknowledgments}

The research team acknowledges the support provided by King Abdul Aziz City for Science and Technology for this research project under research Grant no. AR-27-67. The research team also acknowledges the facilities and support provided by KFUPM. The authors are also thankful to KACST project no. AR-30-291 for providing partial funding.

\section{References}

[1] P. Pokasermsong and P. Praserthdam, "Comparison of activity of Ziegler-Natta catalysts prepared by recrystallization and chemical reaction methods towards polymerization of ethylene," Engineering Journal, vol. 13, no. 1, pp. 57-64, 2009.

[2] J. X. Wong, S. N. Gan, and M. J. Aishah, "Chromium(III) based Ziegler-Natta catalysts for olefin polymerization," Sains Malaysiana, vol. 40, no. 7, pp. 771-779, 2011.

[3] E. Magni and G. A. Somorjai, "Ethylene and propylene polymerization catalyzed by a model Ziegler-Natta catalyst prepared by gas phase deposition of magnesium chloride and titanium chloride thin films," Catalysis Letters, vol. 35, no. 3-4, pp. 205214, 1995.

[4] I. A. Hussein and T. Hameed, "Influence of branching characteristics on thermal and mechanical properties of Ziegler-Natta and metallocene hexene linear low-density polyethylene blends with low-density polyethylene," Journal of Applied Polymer Science, vol. 97, no. 6, pp. 2488-2498, 2005.

[5] T. B. Mikenas, V. A. Zakharov, L. G. Echevskaya, and M. A. Matsko, "Kinetic features of ethylene polymerization over supported catalysts [2,6-Bis(imino)pyridyl iron dichloride/magnesium dichloride] with AlR 3 as an activator," Journal of Polymer Science A, vol. 45, no. 22, pp. 5057-5066, 2007.

[6] J. B. P. Soares and A. E. Hamielec, "Kinetics of propylene polymerization with a non-supported heterogeneous Ziegler-Natta catalyst-effect of hydrogen on rate of polymerization, stereoregularity, and molecular weight distribution," Polymer, vol. 37, no. 20, pp. 4607-4614, 1996.
[7] M. I. Nikolaeva, M. A. Matsko, T. B. Mikenas, L. G. Echevskaya, and V. A. Zakharov, "Copolymerization of ethylene with $\alpha$-olefins over supported titanium-magnesium catalysts. I. Effect of polymerization duration on comonomer content and the molecular weight distribution of copolymers," Journal of Applied Polymer Science, vol. 125, no. 3, pp. 2034-2041, 2012.

[8] V. Zakharov, M. Matsko, L. Echevskaya, and T. Mikenas, "Ethylene polymerization over supported titanium-magnesium catalysts: heterogeneity of active centers and effect of catalyst composition on the molecular mass distribution of polymer," Macromolecular Symposia, vol. 260, pp. 184-188, 2007.

[9] M. I. Nikolaeva, T. B. Mikenas, M. A. Matsko, L. G. Echevskaya, and V. A. Zakharov, "Ethylene polymerization over supported titanium-magnesium catalysts: effect of polymerization parameters on the molecular weight distribution of polyethylene," Journal of Applied Polymer Science, vol. 122, no. 5, pp. 3092-3101, 2011.

[10] L. Moballegh and S. Hakim, "Molecularweight bimodality of ethylene/1-butene in a two-step polymerization process: effects of polymerization conditions," Iranian Polymer Journal, vol. 20, no. 6, pp. 513-521, 2011.

[11] Y. J. Shin, H. X. Zhang, K. B. Yoon, and D. H. Lee, "Preparation of ultra high molecular weight polyethylene with $\mathrm{MgCl}_{2} / \mathrm{TiCl}_{4}$ catalysts: effect of temperature and pressure," Macromolecular Research, vol. 18, no. 10, pp. 951-955, 2010.

[12] B. Wunderlich, "Crystallization during polymerization," Advances in Polymer Science, vol. 5, pp. 568-619, 1968.

[13] A. Muñoz-Escalona and A. Parada, "Factors affecting the nascent structure and morphology of polyethylene obtained by heterogeneous Ziegler-Natta catalysts: 2 . Crystallinity and melting behaviour," Polymer, vol. 20, no. 7, pp. 859-866, 1979.

[14] M. C. Forte and F. M. B. Coutinho, "Highly active magnesium chloride supported Ziegler-Natta catalysts with controlled morphology," European Polymer Journal, vol. 32, no. 2, pp. 223-231, 1996.

[15] T. Hameed and I. A. Hussein, "Rheological study of the influence of MW and comonomer type on the miscibility of mLLDPE and LDPE blends," Polymer, vol. 43, no. 25, pp. 69116929, 2002.

[16] L. H. Sperling, Introduction to Physical Polymer Science, WileyInterscience, New York, NY, USA, 4th edition, 2006. 

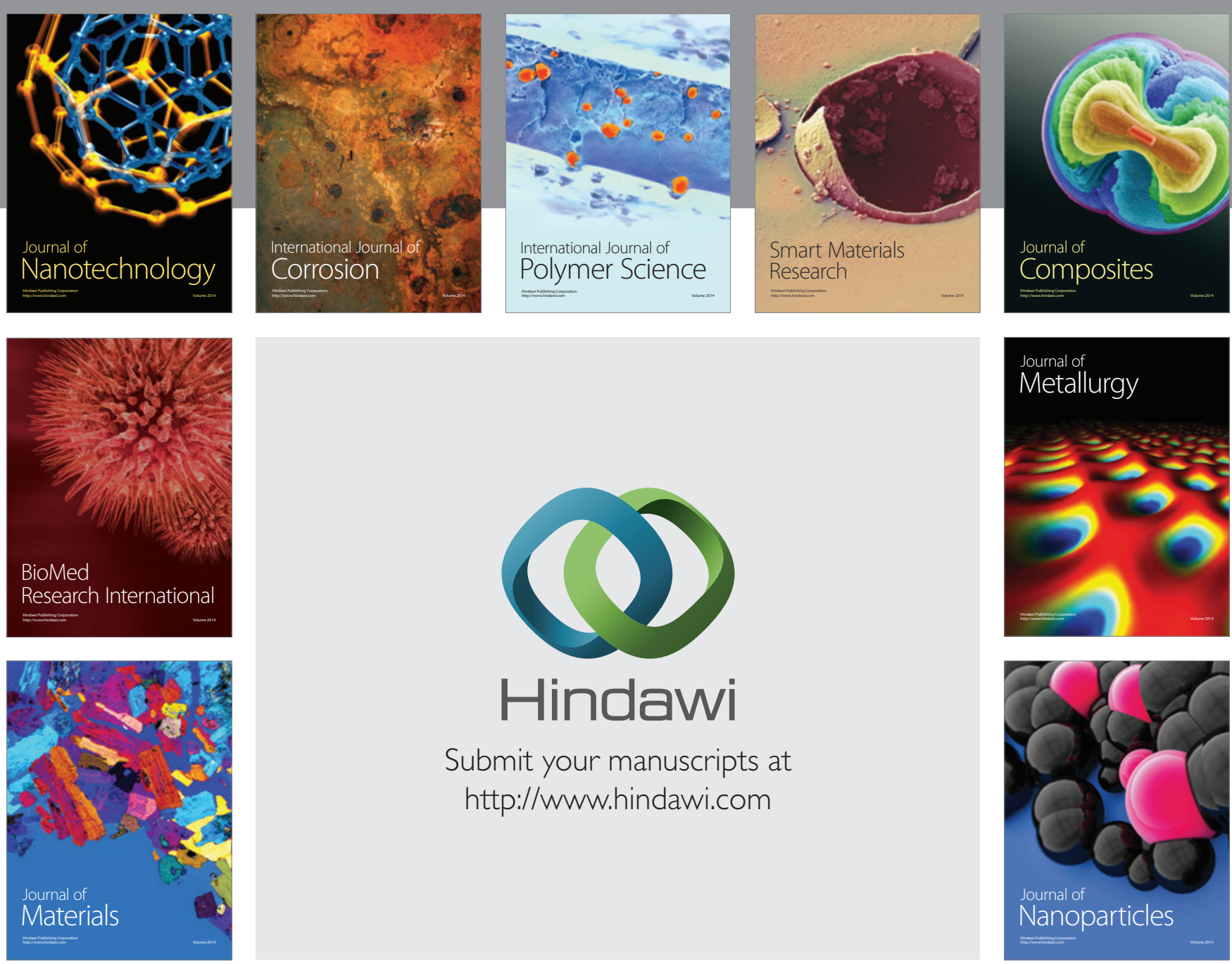

Submit your manuscripts at http://www.hindawi.com
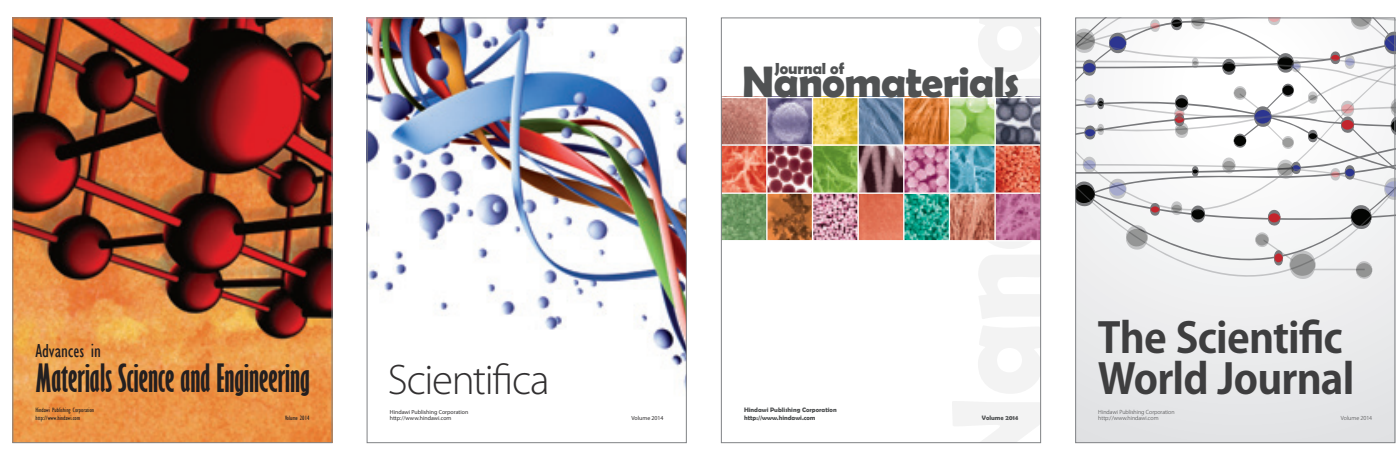

\section{The Scientific World Journal}
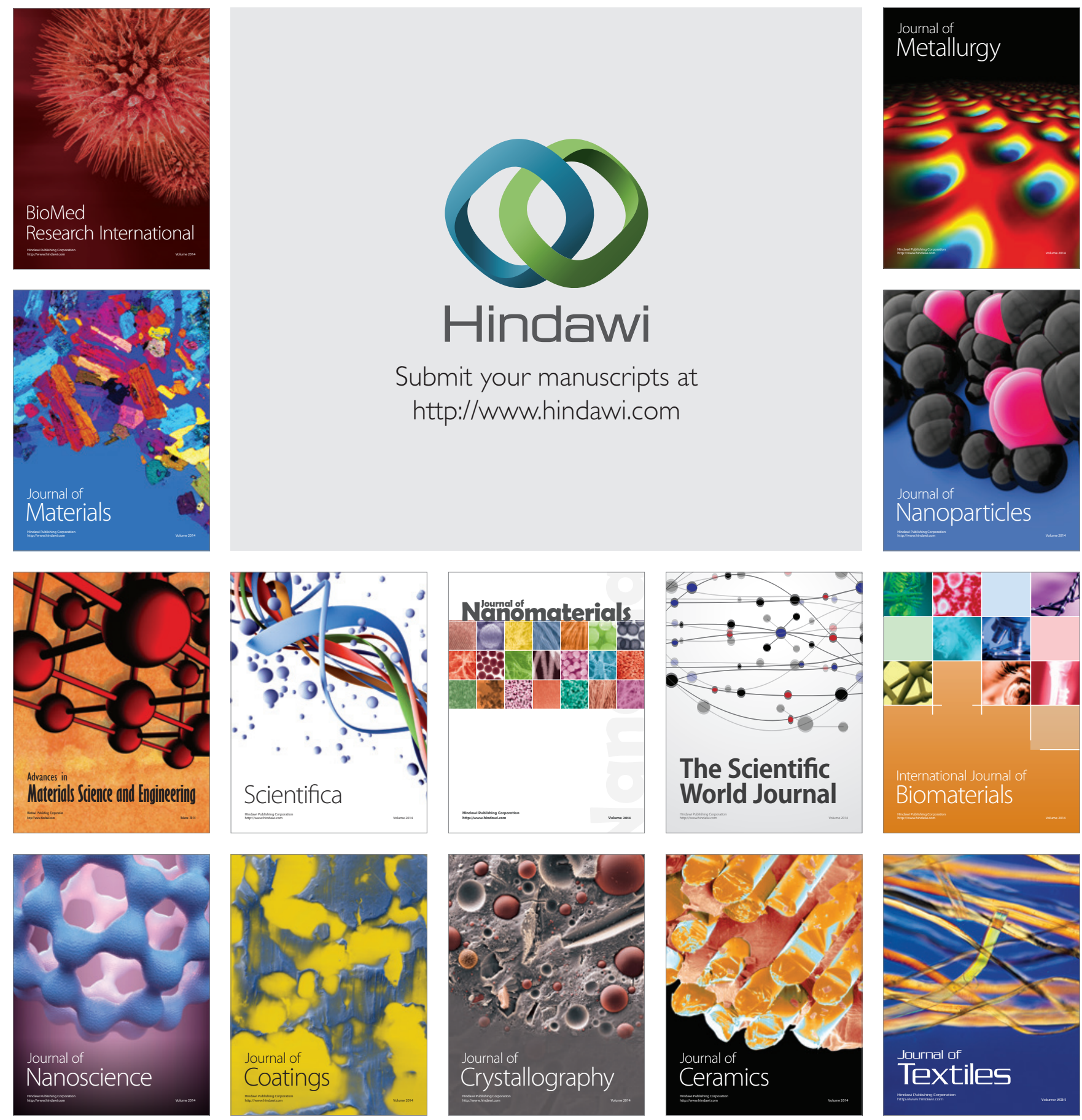